\title{
Group B Streptococcal Tricuspid Valve Endocarditis with Splenic Infarction after an Elective Abortion
}

\author{
P Zhu ${ }^{1}$, Y Sun ${ }^{1,2}$, S Zheng ${ }^{1 *}$
}

\begin{abstract}
Tricuspid valve endocarditis is mainly found in intravenous drug abusers, and with splenic infarction in obstetric and gynecologic practice is rare. We report the case of a 37-year old woman with tricuspid infective endocarditis and splenic infarction after an elective abortion. The infected tricuspid valve and infarcted spleen were removed at one-stage operation. Systemic circulation arterial embolism should be considered when treating patients with right-sided endocarditis and a history of obstetrical procedures.
\end{abstract}

Keywords: Abortion, Group B streptococcus, splenic infarction, tricuspid valve endocarditis

From: ${ }^{1}$ Department of Cardiovascular Surgery, Guangdong General Hospital, Guangdong Academy of Medical Sciences, Guangzhou and ${ }^{2}$ Department of Cardiovascular Surgery, Xiamen Heart Center, Xiamen Cardiovascular Hospital, Xiamen, P.R. China.

*Correspondence: Dr S Zheng, Department of Cardiovascular Surgery, Guangdong General Hospital, Guangdong Academy of Medical Sciences, 96 Dongchuan Road, Guangzhou 510080, P.R. China. Fax: +86 20 83875453; e-mail address: shaoyizheng@yahoo.com 


\begin{abstract}
RESUMEN
Endocarditis de la válvula tricúspide se encuentra principalmente en los consumidores de drogas intravenosas, y con infarto esplénico en la práctica obstétrica y ginecológica es raro. Presentamos el caso de una mujer de 37 años de edad con endocarditis infecciosa tricúspide y infarto esplénico después de un aborto electivo. El bazo de la válvula tricúspide y infartados infectadas fueron retirados en la operación de una etapa. Embolia arterial circulación sistémica se debe considerar en el tratamiento de pacientes con endocarditis derecha y una historia de los procedimientos obstétricos.

Palabras clave: Aborto, el infarto esplénico, endocarditis de la válvula tricúspide, estreptococos del grupo B
\end{abstract}

\title{
INTRODUCTION
}

Tricuspid valve endocarditis is involves the development of huge vegetations with subsequent embolization and obstruction of the pulmonary artery (1). Tricuspid valve endocarditis with splenic infarction due to an elective abortion has been reported in the literature as rare case reports(2-4).We describe and discuss the case of a previously healthy young woman who developed tricuspid valve endocarditis with splenic infarction after an elective termination of pregnancy.

\section{CASE REPORT}

A 37-year female was admitted with a 4-week history of fever, chills, fatigue, and malaise. These symptoms appeared after uterine-incision delivery which was performed following a fetal death during the fifth month of pregnancy. The patient contracted pneumonia after surgery and, because she was allergic to all antibiotics except vancomycin, was treated with 
intravenous vancomycin. Her symptoms failed to resolve after treatment with vancomycin, and she was diverted from another hospital to ours, as her fever could not be controlled.

The physical examination revealed that the patient was in mild respiratory distress. Physical signs included a body temperature of $39-40^{\circ} \mathrm{C}$, a heartbeat of 105 beats per min (bpm), a blood pressure of 100/70 $\mathrm{mm} \mathrm{Hg}$, and tachypnea with normal oxygen saturation in room air. The patient's lungs were clear to auscultation. Examination of the cardiovascular system revealed a grade 3/6 pansystolic murmur at the lower left parasternal border. Pelvic examination showed a normal-sized uterus with closed cervix, no cervical tenderness, and no discharge or anneal masses. The ECG recording revealed sinus tachycardia. Chest X-ray showed a cardiac silhouette of normal size. On transthoracic echocardiography, a large vegetation attached to the anterior tricuspid valve leaflet, with severe regurgitation, was found (figure 1). The patient was deteriorating clinically and was complaining of epigastric pain. A region of splenic infarction was discovered by abdominal ultrasound (figure 2).

Laboratory investigations showed a white blood cell count of 18,000 cells $/ \mathrm{mm}^{3}$ with $79 \%$ segmented neutrophils, hemoglobin concentration of $8 \mathrm{~g} / \mathrm{dL}$, and hematocrit of $28 \%$. The patient's blood cultures were obtained on presentation of fever following uterine-incision delivery in another hospital. GBS infection was suspected, though recurrent blood cultures were negative.

The patient underwent surgery. Following median sternotomy, cardiopulmonary bypass (CPB) was established by cannulation of the aorta and vena cava. Retrograde cardioplegic arrest was achieved after aortic cross clamping. Several large vegetations were attached to the tricuspid valve, resulting in valve destruction. The tricuspid valve was excised 
and a \#29 Cardiomedics standard mechanical mitral valve (CM; Sorin Biomedica Cardio S.R.L., Saluggia, Italy) was implanted. Splenectomy was initiated by a general surgeon after the chest sutures were in place.

The postoperative course was uneventful, except for a low fever lasting 3 days. Four weeks of antibiotic therapy were completed, and the patient was doing well at the time of follow-up.

\section{DISCUSSION}

Although right-sided infective endocarditis usually affects drug addicts without any preexisting heart disease, gynecologic infections have been reported as the source of this condition(2). The tricuspid valve is the most common right-sided valve involved in endocarditis, either alone, or in conjunction with, the pulmonic valve (1). However, rare instances of tricuspid valve endocarditis with splenic infarction have been reported. The tricuspid valve involvement in our patient resulted from transmission of bacteria from the septic uterus, through the pelvic veins, and into the venous system. Splenic infarction may have resulted from embolic detachment of the mitral valve vegetation, although no sign of this was found by pre-surgical transthoracic echocardiography.

The incidence of infective endocarditis after obstetric and gynecological procedures is low, ranging from 0.03 to 0.14 per 1000 deliveries, and is especially lower after abortions. Reports of streptococcal endocarditis involving the tricuspid valve are very rare (5). In most cases, the vegetations are visible by either transthoracic or transesophageal echocardiography. 
Because the sensitivity of transesophageal echocardiography is substantially higher than that achieved by the transthoracic approach, the American Heart Association has declared transesophageal echocardiography the "gold standard" for the diagnosis of endocarditis (6). Splenic infarction is a grave complication of left-sided infective endocarditis, and is rarely involved with tricuspid valve endocarditis. Splenic infarctions may be diagnosed easily by abdominal ultrasound.

The drug of choice in the treatment of streptococcal endocarditis is penicillin combined with aminoglycoside, and the indication for surgery is less established than in left-sided streptococcal endocarditis, for which early operation is recommended (7). The successful treatment of tricuspid endocarditis should include the excision of all infected tissue and restoration of valvular function. In this patient, the valve was excised and replaced due to ongoing antibiotic-resistant infection, destruction of the valve through abscess formation, and worsening of the tricuspid regurgitation.

The management of tricuspid valve endocarditis with splenic infarction remains a topic of debate, because no reports clearly favor either simultaneous splenectomy or a two-stage approach. For surgeries requiring extended operating times, some general surgeons have suggested performing staged procedures to minimize complications of wound infections, especially bleeding after cardiopulmonary bypass. We choice one -stage approach, and the patients has excellent late outcome. In addition, the simultaneous operation resulted in significant decreases in procedural cost and associated pain. 


\section{CONCLUSION}

Tricuspid infective endocarditis with splenic infarction after an elective abortion is rare. women of childbearing age have gained great benefits from prophylactic antibiotics prior to abortion and routine screening for Group B streptococcus. One-stage tricuspid valve replacement and splenectomy were performed successfully with resulting improvement in quality of life.

\section{ACKNOWLEDGEMENTS}

The authors are grateful to Jing Shang from the department of Obstetrics and Gynecology for his useful suggestions about cure suggestion.

Conflict of interest: none 


\section{REFERENCES}

1. Aslam AF,Aslam AK,Thakur AC,Vasavada BC,Khan IA.Staphylococcus aureus infective endocarditis and septic pulmonary embolism after septic abortion.Int $\mathbf{J}$ Cardiol 2005; 105: 233-235.

2. Erica E.Palys,John Li,Paula L.Gaut,W.David Hardy. Tricuspid valve endocarditis with group B streptococcus after an elective abortion: The need for new data.Infect Dis Obstet Gynecol.2006; 2006: 1-3.

3. Patil N,Martin RE.Native aortic valve infective endocarditis caused by Streptococcus agalactiae in a renal transplant recipient. Am J Med Sci 2010; 340: $518-20$.

4. Farley MM,Harvey C,Stull T. A population-based assessment of invasive disease due to group B streptococcus in nonpregnant adults. N Engl J Med 1993; 328: 1807-11.

5. Vartian CV,Septimus EJ.Tricuspid valve Group B streptococcal endocarditis following elective abortion.Rev Infect Dis 1991;13:997-8.

6. Robbins MJ,Soeiro R,Frishman WH,Strom JA. Right-sided valvular endocarditis: etiology, diagnosis, and an approach to therapy. Am Heart J 1986:111; 128-35.

7. Wilson WR,Karchmer AW,Dajani AS,Taubert KA,Bayer A,Kaye D,et al.Antibiotic treatment of adults with infective endocarditis due to streptococci,enterococci,staphylococci and HACEK microorganisms. JAMA 1995; 274:1706-13 


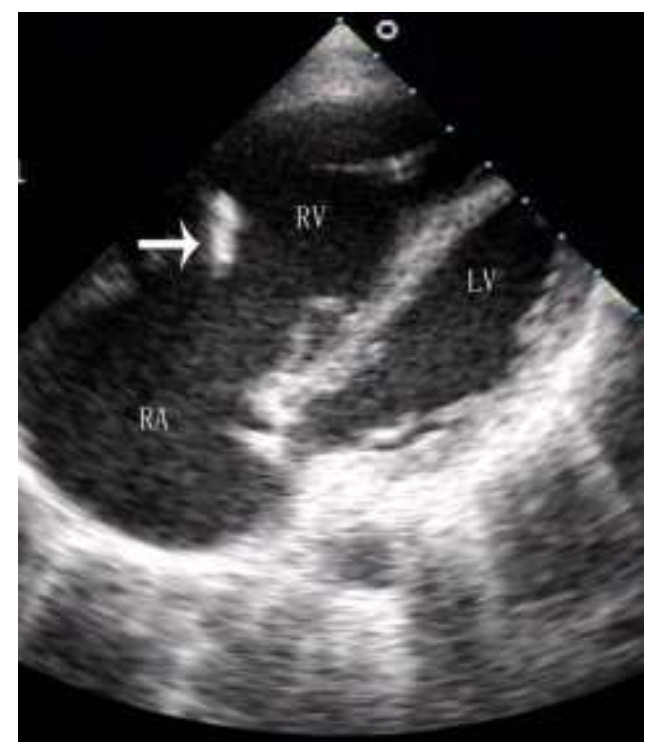

Figure 1.Transthoracic echocardiography. Transthoracic echocardiography shows large vegetation attanched to the anterior leaflet of the tricuspid valve and flying between the right atrium and ventricle (white arrow).

$\mathrm{LA}=$ left atrium; $\mathrm{RA}=$ right atrium; $\mathrm{RV}=$ right ventricle

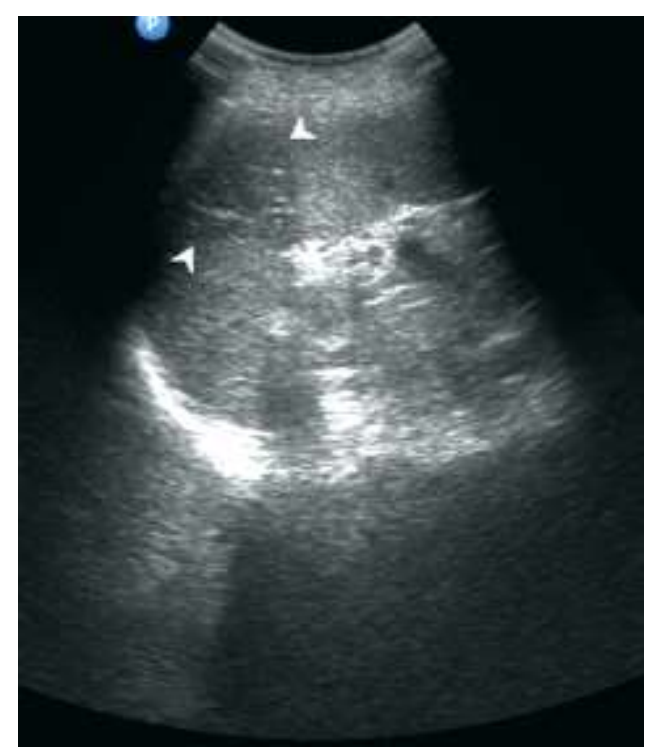

Figure 2. Large splenic infarcts was demonstrated on an abdominal ultrasound (white arrow). 